\title{
Calculation of the Growth Efficiency of China's Regional Industry Considering the Constraints of Exhaustible Resources
}

\author{
Xiaochen Zhu, a , Shuyu Sun ${ }^{1, b}$ and Wanhong $\mathrm{Li}^{1, \mathrm{c}}$ \\ ${ }^{1}$ School of Economics and Management, Harbin Engineering University, Harbin, China \\ a zhuxiaochenheu@126.com, ${ }^{\mathrm{b}}$ sunshuyu@163.com, ${ }^{\mathrm{c}}$ liwanhong@hrbeu.edu.cn
}

\begin{abstract}
Keywords: exhaustible resources; industrial growth efficiency; total factor productivity; SBM model; Malmquist-Luenberger index.

Abstract. Based on the SBM model and the Malmquist-Luenberger index operation, this paper analyzes the regional industrial growth efficiency from static and dynamic aspects. For static efficiency, the overall efficiency of industrial growth in China shows a trend of decreasing from east to west. The pure technical efficiency in the middle is the lowest and the scale efficiency in the west is higher while its overall efficiency is low. The differences within the central provinces are the smartest. For dynamic efficiency, the industrial TFP growth rate is from west to east in the order of high to low and the TFP of different provinces varies greatly.
\end{abstract}

\section{Introduction}

Exhaustible resources are an important material basis for the development of a country's industrial economy. However, the total amount of exhaustible resource tends to be less and its utilization efficiency is lower in China. Besides, there is a clear regional difference in the efficiency of industrial growth under the constraints of exhaustible resources. Therefore, it is of great significance for China to cope with the severe challenges of depletion of exhaustible resources and to promote the coordinated development of regional economy under the constraints of exhaustible resources.

Based on the idea of "resource constraints", scholars explored the relationship between exhaustible resource constraints and economic growth. These views can be divided into two perspectives, "resource curse" and the opposition. In addition, domestic and foreign scholars began to pay more attention to the measurement of economic growth under the influence of resources and environment. Especially for the study of regional economic differences, scholars use different methods to test the impact of resource elements on efficiency to obtain more realistic economic growth efficiency. Ertugrul (2016) used a production function model to evaluate the efficiency of resource inputs in developing countries ${ }^{[1]}$. Nicola (2016) found that resource efficiency is closely related to economic growth and technological progress ${ }^{[2]}$.

In summary, the exhaustible resources constraints and their industrial growth issues were discussed in depth in the existing literature and made a wealth of research results. But the following remains to be studied: (1) In addition to the traditional input elements and the environment variables, few studies consider natural resource elements closely related to industrial sustainable development, and the issue of exhaustible resource constraints has not received enough attention. (2) Although most scholars have adopted the DEA model to comprehensively analyze the efficiency and TFP, but they only selected radial and angular efficiency measurement method and neglected the slack problem of unit input and output. (3) The study of industrial growth efficiency was focused on the industry and at the national and provincial levels, with very few studies in the area. Therefore, regarding the issue above, this paper puts the traditional input elements and the regional industrial growth efficiency considering the exhaustible resource elements into a unified research framework and analyzes the regional industrial growth efficiency levels from both static and dynamic aspects respectively. Secondly, it decomposes industrial growth efficiency and TFP, explores the current situation and dynamic evolution trend of industrial growth efficiency in different regions of China, and explores the sources of inefficiency of industrial growth in different regions, to provide the basis for making coordinated development between resource saving and economic growth in China's industry. 


\section{Methodology and Variable Description}

Methodology. Tone (2001) proposed a slack-based model (SBM), which is a slack-based DEA model. The SBM model adds slack variables to the objective function directly ${ }^{[3]}$. Compared with DEA, it relies on input-output data to obtain the corresponding technical front and efficiency evaluation of decision-making unit (DMU) relative to reference technologies, so there is no need to set the optimal behavior goal of the producer and make a special assumption on the form of a production function. Using the SBM model to measure the efficiency of a $\operatorname{DMU}\left(\mathrm{x}_{0}, \mathrm{y}_{0}\right)$ with $\mathrm{m}$ inputs and $\mathrm{s}$ outputs, feasible production set $\mathrm{P}$ can be defined as follows:

$$
P=\{(x, y) \mid x \geq X \lambda, y \leq Y \lambda, \lambda \geq 0\} .
$$

The expression of the SBM model is as follows:

$$
\begin{aligned}
& \rho^{*}=\min \frac{1-\frac{1}{m} \sum_{k=1}^{m} \frac{s_{k}^{-}}{\chi_{i 0}}}{1+\frac{1}{s} \sum_{r=1}^{s} \frac{s_{r}^{+}}{y_{r 0}}} . \\
& \text { s.t. }\left\{\begin{array}{l}
x_{0}=X \lambda+s^{-} \\
y_{0}=Y \lambda-s^{+}
\end{array}\right. \text {. }
\end{aligned}
$$

Chung et al. (1997) summarize the profit function of Luenberger (1992) and propose a new non-radial approach and the directional distance function can handle the simultaneous changes in inputs and outputs ${ }^{[4]}$. The Malmquist-Luenberger (ML) productivity index is a dynamic analysis that analyzes the relative position (changes in efficiency) to the production boundary and shifts to production boundaries (technological advances) of each province. The Malmquist-Luenberger productivity index is expressed as follows:

$$
M L_{t}^{t+1}=\left[\frac{1+\stackrel{r}{D_{0}^{t}}\left(x^{t}, y^{t}, z^{t} ; y^{t},-z^{t}\right)}{\stackrel{r}{D}_{0}^{t+1}\left(x^{t+1}, y^{t+1}, z^{t+1} ; y^{t+1},-z^{t+1}\right)} \times \frac{1+\stackrel{r}{D_{0}^{t+1}}\left(x^{t}, y^{t}, z^{t} ; y^{t},-z^{t}\right)}{1+D_{0}^{t+1}\left(x^{t+1}, y^{t+1}, z^{t+1} ; y^{t+1},-z^{t+1}\right)}\right] .
$$

ML index can be decomposed into technical efficiency index (EFFCH) and technical progress index (TECH), the decomposition formula is as follows:

$$
\begin{aligned}
& \operatorname{EFFCH}_{t}^{t+1}=\frac{1+\stackrel{1}{D_{0}^{t}}\left(x^{t}, y^{t}, z^{t} ; y^{t},-z^{t}\right)}{1+D_{0}^{t}\left(x^{t+1}, y^{t+1}, z^{t+1} ; y^{t+1},-z^{t+1}\right)} .
\end{aligned}
$$

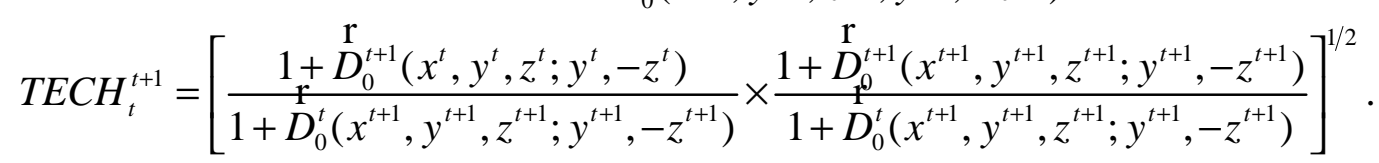

ML greater than 1 means that the overall production efficiency has improved; EFFCH greater than 1 means that the technical efficiency is on the rise; and TECH greater than 1 means the production technology is improved. Conversely, the corresponding efficiency is deteriorating.

\section{Variable Selection and Description.}

Input element indicators. First, capital investment elements. Based on the research of Zhang Jun et al., this paper uses perpetual inventory method to estimate the capital stock, strictly distinguishes the mode of declining efficiency of capital goods and uses gross fixed capital formation as the current investment indicators ${ }^{[5]}$ and deflate when 1978 was the base period. The unit is ten thousand yuan.

Second, labor input elements. Learning from the method used by Ma Hailiang et al. (2011) when dealing with labor input, the average number of employed people who work from the beginning of the year to the end of the year is used to indicate the number of employed people in the year. This paper uses "industrial labor productivity = industrial added value / employees" to calculate the corresponding 
number of industrial workers ${ }^{[6]}$.

Third, the total consumption of exhaustible resources. As the total exhaustible resources are difficult to count, the total amount of production of the three most exhaustible fossil fuels (coal, oil and natural gas) in various regions is used as an indicator of the total supply of exhaustible resources.

Output element indicators. In this paper, industrial added value is used as a measure of the output indicator of industrial growth efficiency, which is not double counted with other sectors compared with the gross industrial output value.

\section{Empirical Process and Result Analysis}

Data Sources. This paper chooses the industrial sectors of 29 provinces, cities and regions (Xinjiang and Tibet are excluded and Chongqing will be merged with Sichuan Province because of lack of data.) in China over the period 2005-2014. The data are taken from China Statistical Yearbook, China City Statistical Yearbook and China Energy Statistical Yearbook and set 1978 as the base period. This paper uses MaxDeapro to perform operation, and specific analysis of the calculation results is as follows.

\section{Static Efficiency Analysis.}

Regional static efficiency differences. There are obvious regional differences in the efficiency of industrial growth in China, so it is necessary to analyze the differences in regional efficiency to study the efficiency of industrial growth to guide the regions with low efficiency to enhance their efficiency. This paper gets the efficiency of industrial growth in different regions of the east, middle and west.

Fig. 1 shows the time series changes of the overall efficiency of China's industrial growth under the constraints of exhaustible resources. The growth efficiency of the industrial economy in the east is above the national average while that in the central region is slightly below the national average and the overall efficiency of the western region is low. As an area with the highest industrial growth efficiency in China, the overall efficiency value in the eastern region is between 0.7 and 0.8 . Obviously, the challenge of China's industrial economic growth is still huge, but it also means that there is potential for China's regional industrial growth.

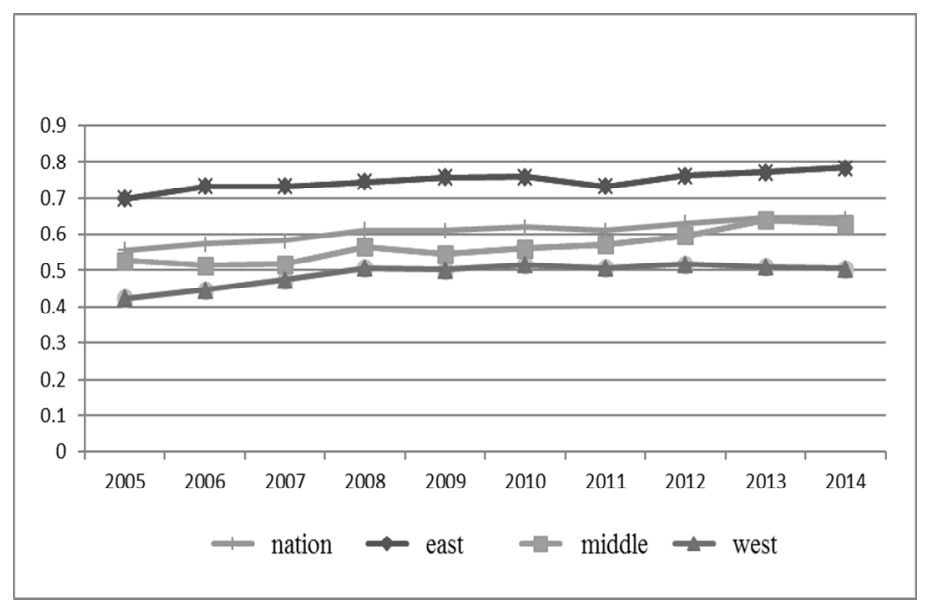

Fig. 1 China's three major regional industrial growth efficiency trends

Table 1 shows the decomposition of regional industrial growth efficiency in China. Overall, from 2005 to 2014, the overall scale efficiency level is all under the production frontier, element configuration structure of input is irrational, and there is redundancy at the configuration level under the constraints of exhaustible resources in China's three major regions. The result is more in line with actual economic situation in the middle, east and west of China. The development of the eastern coastal areas is earlier than that of the inland areas, so eastern coastal areas have great advantages in terms of economic output, talent pool and resource allocation. For the central and western regions, there is still a long way to go when compared with the eastern region in terms of economic development and the 
use of science and technology to improve the efficiency of resource allocation. Although the overall efficiency of the central region is higher than that of the western region, the purely technical efficiency of the central region is lower than that of the western region. Therefore, industrial economic development in the central region is still relatively extensive. The overall efficiency of the western region is relatively low, but its scale efficiency is the highest among the three regions in the past five years, which shows that economic efficiency in the western region is too dependent on the supply of exhaustible resources and is not advisable in the long term. Therefore, the western region should look for a more rational economic model, advocate energy conservation and emission reduction, and step up efforts to increase industrial output from the perspective of increasing technological input.

Table 1 China's three major regional industrial growth efficiency and decomposition

\begin{tabular}{c|c|c|c|c|c|c|c|c|c|c|c}
\hline Efficiency type & Region & 2005 & 2006 & 2007 & 2008 & 2009 & 2010 & 2011 & 2012 & 2013 & 2014 \\
\hline \multirow{4}{*}{$\begin{array}{c}\text { Overall } \\
\text { efficiency }\end{array}$} & East & 0.699 & 0.733 & 0.732 & 0.745 & 0.757 & 0.758 & 0.733 & 0.761 & 0.771 & 0.784 \\
\cline { 2 - 12 } & Middle & 0.527 & 0.515 & 0.517 & 0.565 & 0.545 & 0.561 & 0.571 & 0.597 & 0.639 & 0.629 \\
\cline { 2 - 12 } & West & 0.424 & 0.446 & 0.474 & 0.507 & 0.502 & 0.516 & 0.507 & 0.517 & 0.510 & 0.505 \\
\cline { 2 - 12 } & Nation & 0.556 & 0.573 & 0.583 & 0.612 & 0.610 & 0.619 & 0.610 & 0.631 & 0.644 & 0.644 \\
\hline \multirow{4}{*}{$\begin{array}{c}\text { Overall } \\
\text { efficiency }\end{array}$} & East & 0.909 & 0.906 & 0.926 & 0.932 & 0.942 & 0.955 & 0.951 & 0.978 & 0.973 & 0.983 \\
\cline { 2 - 11 } & Middle & 0.678 & 0.657 & 0.659 & 0.660 & 0.652 & 0.691 & 0.706 & 0.729 & 0.765 & 0.753 \\
\cline { 2 - 11 } & West & 0.737 & 0.689 & 0.791 & 0.804 & 0.823 & 0.844 & 0.857 & 0.862 & 0.851 & 0.845 \\
\cline { 2 - 11 } & Nation & 0.785 & 0.761 & 0.804 & 0.812 & 0.820 & 0.843 & 0.850 & 0.868 & 0.873 & 0.871 \\
\hline \multirow{4}{*}{ Scale efficiency } & East & 0.773 & 0.800 & 0.792 & 0.804 & 0.806 & 0.800 & 0.778 & 0.781 & 0.797 & 0.800 \\
\cline { 2 - 11 } & Middle & 0.760 & 0.772 & 0.780 & 0.847 & 0.832 & 0.807 & 0.807 & 0.814 & 0.824 & 0.820 \\
\cline { 2 - 10 } & West & 0.737 & 0.689 & 0.791 & 0.804 & 0.823 & 0.844 & 0.857 & 0.862 & 0.851 & 0.845 \\
\cline { 2 - 10 } & Nation & 0.785 & 0.761 & 0.804 & 0.812 & 0.820 & 0.843 & 0.850 & 0.868 & 0.873 & 0.871 \\
\hline
\end{tabular}

Through the calculation of the standard deviation and the extremum of the overall efficiency, pure technical efficiency and scale efficiency in the eastern, central and western regions, we can see that, the efficiency gap between the provinces in the central region is small, and there are large differences in efficiency among the provinces in the eastern and western regions. Tianjin and Guangdong $(\mathrm{TE}=1)$, which have the highest relative efficiency, are 0.7809 higher than the least-efficient Hainan $(\mathrm{TE}=$ 0.219). The efficiency gap between the provinces in the eastern region excluding Hainan Province is the smallest, followed by the central region, while the western region has the highest internal differentiation.

Table 2 The Standard Deviations and Extreme Values of Industrial Growth Efficiency in Three Regions of China

\begin{tabular}{c|c|c|c|c|c|c}
\hline \multirow{2}{*}{ Region } & \multicolumn{2}{|c|}{ Overall efficiency } & \multicolumn{2}{c|}{ Pure technical efficiency } & \multicolumn{2}{c}{ Scale efficiency } \\
\cline { 2 - 7 } & Standard deviation & Extremum & Standard deviation & Extremum & Standard deviation & Extremum \\
\hline East & 0.2648 & 0.7809 & 0.0889 & 0.2519 & 0.2656 & 0.7809 \\
\hline Middle & 0.1059 & 0.2948 & 0.0771 & 0.2441 & 0.0861 & 0.2774 \\
\hline West & 0.2653 & 0.8673 & 0.2005 & 0.6111 & 0.2717 & 0.8338 \\
\hline
\end{tabular}

Provincial static efficiency differences. To compare the differences in the static efficiency of provincial regions, the efficiency differences in industrial growth in terms of provinces are discussed.

From Table 3, the overall efficiency of Tianjin, Guangdong and Sichuan is 1 during 2005-2014, which is valid for DEA. The overall efficiency of Zhejiang, Fujian and Shandong are also high, with the efficiency values higher than 0.9, Guizhou, Ningxia, Qinghai, Gansu and Hainan have the lowest efficiency, while the efficiency value of Beijing is also low slightly. Shanghai, Fujian, Shandong, Hainan and Ningxia are purely technically effective, not scale-effective, indicating that the current output cannot be reduced any more, and the remaining non-technically effective and non-scale effective provinces exist redundant input or insufficient output, indicating that it is possible to keep the current output level even if some of the input is reduced. 
Table 3 Decomposition and Ranking of Industrial Growth Efficiency of Provinces in China

\begin{tabular}{|c|c|c|c|c|c|c|c|}
\hline Region & Province & $\begin{array}{l}\text { Overall } \\
\text { efficiency }\end{array}$ & $\begin{array}{l}\text { Efficiency } \\
\text { ranking }\end{array}$ & $\begin{array}{c}\text { Pure } \\
\text { technical } \\
\text { efficiency }\end{array}$ & $\begin{array}{l}\text { Efficiency } \\
\text { ranking }\end{array}$ & $\begin{array}{c}\text { Scale } \\
\text { efficiency }\end{array}$ & $\begin{array}{l}\text { Efficiency } \\
\text { ranking }\end{array}$ \\
\hline \multirow{11}{*}{ East } & Tianjin & 0.3501 & 24 & 0.9756 & 11 & 0.3599 & 21 \\
\hline & Hebei & 1 & 1 & 1 & 1 & 1 & 1 \\
\hline & Liaoning & 0.6524 & 11 & 0.7481 & 19 & 0.8747 & 8 \\
\hline & Shanghai & 0.6315 & 13 & 0.7835 & 17 & 0.8043 & 12 \\
\hline & Jiangsu & 0.5929 & 16 & 1 & 1 & 0.5922 & 19 \\
\hline & Zhejiang & 0.8893 & 8 & 0.9082 & 14 & 0.9774 & 4 \\
\hline & Fujian & 0.973 & 6 & 0.9853 & 10 & 0.9849 & 3 \\
\hline & Shandong & 0.9229 & 7 & 1 & 1 & 0.9229 & 6 \\
\hline & Guangdong & 0.9895 & 5 & 1 & 1 & 0.9895 & 2 \\
\hline & Hainan & 1 & 1 & 1 & 1 & 1 & 1 \\
\hline & Shanxi & 0.2191 & 26 & 1 & 1 & 0.2191 & 25 \\
\hline \multirow{8}{*}{ Middle } & Jilin & 0.5549 & 18 & 0.6714 & 25 & 0.8248 & 11 \\
\hline & $\begin{array}{c}\text { Heilongjia } \\
\text { ng }\end{array}$ & 0.4405 & 23 & 0.6059 & 27 & 0.7252 & 16 \\
\hline & Anhui & 0.6390 & 12 & 0.8155 & 16 & 0.7723 & 14 \\
\hline & Jiangxi & 0.6053 & 15 & 0.7145 & 21 & 0.8399 & 10 \\
\hline & Henan & 0.4428 & 22 & 0.6732 & 24 & 0.6583 & 18 \\
\hline & Hubei & 0.6641 & 10 & 0.7266 & 20 & 0.9115 & 7 \\
\hline & Hunan & 0.4498 & 21 & 0.5715 & 28 & 0.7838 & 13 \\
\hline & $\begin{array}{c}\text { Inner } \\
\text { Mongolia }\end{array}$ & 0.7353 & 9 & 0.7813 & 18 & 0.9357 & 5 \\
\hline \multirow{9}{*}{ West } & Guangxi & 0.5839 & 17 & 0.6758 & 23 & 0.8568 & 9 \\
\hline & Sichuan & 0.4541 & 20 & 0.6762 & 22 & 0.6707 & 17 \\
\hline & Guizhou & 1 & 1 & 1 & 1 & 1 & 1 \\
\hline & Yunnan & 0.1326 & 29 & 0.3888 & 29 & 0.3447 & 22 \\
\hline & Shaanxi & 0.5080 & 19 & 0.9504 & 13 & 0.5425 & 20 \\
\hline & Gansu & 0.6131 & 14 & 0.8437 & 15 & 0.7301 & 15 \\
\hline & Qinghai & 0.2043 & 27 & 0.6143 & 26 & 0.3373 & 23 \\
\hline & Ningxia & 0.1556 & 28 & 0.9551 & 12 & 0.1662 & 26 \\
\hline & Tianjin & 0.2558 & 25 & 1 & 1 & 0.2558 & 24 \\
\hline
\end{tabular}

Dynamic Efficiency Analysis. Under the influence of various factors, the production frontier constantly changes over time so it is necessary to analysis the changes in the production frontier and its impact on various efficiency.

Regional dynamic efficiency differences. From Table 4, the TFP of China's industry has increased by $6.9 \%$ annually under the constraint of exhaustible resources and $6.7 \%, 6.2 \%$ and $8.0 \%$ respectively in the eastern, central and western regions. Among them, the industrial TFP growth in the western region was the fastest, followed by the eastern region, while that in the central region was the slowest. Moreover, the industrial TFP growth in China and the three major regions is mainly due to cutting-edge technological progress.

The mean value of TFP in the western region was 1.080, higher than the national average and is the highest in China, resulting from the improvement of technical efficiency. 
Table 4 2005-2014 China's regional industrial average TFP and decomposition

\begin{tabular}{c|c|c|c|c}
\hline DMU & TFP & technical efficiency & technical progress & scale efficiency changes \\
\hline Eastern average & 1.067 & 1.000 & 1.068 & 0.996 \\
\hline Middle average & 1.062 & 1.005 & 1.057 & 0.997 \\
\hline Western average & 1.080 & 1.011 & 1.068 & 0.999 \\
\hline average value & 1.069 & 1.005 & 1.064 & 0.997 \\
\hline
\end{tabular}

Provincial dynamic efficiency differences. From Table 5, the TFP of all provinces varies from 0.988 to 1.154 , with a big gap among provinces. Under the current productivity conditions in China, the provinces with the highest overall efficiency tend to hold the optimal technology for energy use, which is the most intensive mode of economic growth that can be achieved compared to other provinces. However, the TFP of the eastern provinces is not high according to the rankings. The reason may be that excessive input of exhaustible resources in the eastern region leads to high carbon emissions, resulting in the inefficiency of industrial growth caused by environmental pollution control costs. All provinces are in a state that TFP is valid except Hainan and Heilongjiang.

Table 5 TFP in China's provinces and ranking

\begin{tabular}{c|c|c|c|c|c|c|c|c}
\hline Ranking & East & TFP & Ranking & Middle & TFP & Ranking & West & TFP \\
\hline 3 & Beijing & 1.137 & 25 & Shanxi & 1.002 & 1 & $\begin{array}{c}\text { Inner } \\
\text { Mongolia }\end{array}$ & 1.154 \\
\hline 11 & Tianjin & 1.078 & 10 & Jilin & 1.085 & 18 & Guangxi & 1.050 \\
\hline 5 & Hebei & 1.105 & 27 & $\begin{array}{c}\text { Heilongji } \\
\text { ang }\end{array}$ & 0.988 & 8 & Sichuan & 1.096 \\
\hline 19 & Liaoning & 1.046 & 9 & Anhui & 1.092 & 2 & Guizhou & 1.150 \\
\hline 24 & Shanghai & 1.017 & 13 & Jiangxi & 1.074 & 22 & Yunnan & 1.036 \\
\hline 5 & Jiangsu & 1.105 & 15 & Henan & 1.068 & 17 & Shaanxi & 1.060 \\
\hline 14 & Zhejiang & 1.071 & 12 & Hubei & 1.077 & 15 & Gansu & 1.068 \\
\hline 19 & Shandong & 1.046 & 4 & Hunan & 1.107 & 23 & Qinghai & 1.032 \\
\hline 21 & Fujian & 1.045 & & & & 6 & Ningxia & 1.103 \\
\hline 26 & Hainan & 0.993 & & & & & & \\
\hline 7 & $\begin{array}{c}\text { Guangdo } \\
\text { ng }\end{array}$ & 1.100 & & & & & & \\
\hline
\end{tabular}

\section{Conclusions}

Combining the SBM model with the Malmquist-Luenberger index operation, this paper measures industrial growth efficiency and TFP in each region in China from 2005 to 2014 by using the data of China's provinces, and analyzes the efficiency differences among China's eastern, central and western regions and in each province from the static and dynamic perspectives.

For static efficiency, the overall efficiency of industrial growth in the three major regions is eastern, central and western region in descending order under the constraint of exhaustible resources. By decomposing the efficiency of industrial growth in all regions, it was found that the development in the eastern region was earlier than that in the central and western regions, and its factor allocation structure was more reasonable. Although the exhaustible resource reserves in the central and western regions had some advantages, the purely technical efficiency of the central part is lower than that of the western part, showing that its industrial economic development is still relatively extensive, and the scale efficiency in the western region are the highest among the three regions in the past five years, indicating that they rely too much on the supply of exhaustible resources. Besides, there is differentiation within each region, and provinces in the central region has the smallest efficiency gap. Due to the relatively low efficiency in Hainan Province, the efficiency gap in the eastern region is widened. The internal differentiation in the western region is the largest. 
For dynamic efficiency, the total industrial factor productivity growth rate of the three regions is from west to east in the order of high to low, and the industrial TFP growth in the three major regions are mainly derived from cutting-edge technological progress. The TFP in the western region is higher because of its technical efficiency improvement. The TFP of different provinces varies greatly, but all provinces are in an effective state of TFP except Hainan and Heilongjiang. The eastern region has the highest overall efficiency but may have a large amount of carbon emissions due to its over-invested exhaustible resources, which increases the cost of environmental pollution control and makes TFP not high, while the TFP of some western provinces is very high.

In short, this paper explores the current situation and dynamic evolution trend of industrial growth efficiency in different regions of China and explores the sources of inefficiency of industrial growth in different regions, to provide the basis for making coordinated development between resource saving and economic growth in China's industrial sector. In addition, since the capital stock is a very important indicator when calculating factor energy efficiency, the measurement of this indicator merits further exploration.

\section{Acknowledgements}

This research was supported by funding from the National Social Science Foundation of China (NO.17BGL204) and the Philosophy \& Social Science Project of Heilongjiang Province (NO.16JYB04).

\section{References}

[1] Ertugrul Deliktas, Gülçin Gürel Günal. Economic Growth and Input Use Efficiency in Low, Upper -Middle and High Incomed Countries (1991-2011): A Data Envelopment Analysis[J]. Procedia Economics and Finance,2016, (2):180-205.

[2] Nicola Cantore,Massimiliano Calì,Dirk Willem te Velde. Does energy efficiency improve technological change and economic growth in developing countries? [J]. Energy Policy,2016, (06):21-37.

[3] Tone, Z.F., M.S.Khan. A Slacks-based Measure of Efficiency in Data Envelopment Analysis[J]. European Journal of Operational Research.2001,130:498-509.

[4] Chung,Y.H., R.Fare., S.Grosskopf. Productivity and undesirable outputs:a directional distance function approach[J].Journal of Environmental Management,1997, (51):229-240.

[5] Jun Zhang. Estimation of China's provincial capital stock (1952-2004) with applications[J]. Journal of Chinese Economic \& Business Studies, 2008, 6(2):177-196. (in Chinese)

[6] Ma Hailiang, Huang Dechun, Yao Huize.Research on total factor energy efficiency in China's three major economic regions-based on the super efficiency DEA model and the Malmquist index [J], China Population, Resources and Environment, 2011, (11): 38-43. (in Chinese) 